\title{
Yetişkin Yoğun Bakım Ünitelerinde Santral Kateter İlişkili Kan Dolaşımı Enfeksiyonlarının Önlenmesi: Sistematik Derleme
}

\section{Prevention of Central Line-Associated Bloodstream Infection in Adult Intensive Care Units: A Systematic Review}

\author{
Aysun Acun ${ }^{1}$, Nurcan Çalışkan ${ }^{2}$
}

${ }^{1}$ Bilecik Seyh Edebali Üniversitesi, Sağlık Bilimleri Fakültesi, Hemşirelik Bölümü, Bilecik, Türkiye

${ }^{2}$ Gazi Üniversitesi, Sağlık Bilimleri Fakültesi, Hemşirelik Bölümü, Ankara, Türkiye

Yazışma Adresi: Aysun Acun, Bilecik Şeyh Edebali Üniversitesi, Sağlık Bilimleri Fakültesi, Hemşirelik Bölümü, Bilecik, Türkiye e-posta: aysun.acun@bilecik.edu.tr

Geliş Tarihi/Received: 20 Nisan 2021 Kabul Tarihi/Accepted: 31 Temmuz 2021

\section{Öz}

Bu derlemenin amacı, santral kateter ilişkili kan dolaşımı enfeksiyonlarını önlemeye yönelik yapılan ve yayınlanan müdahale çalışmalarının sistematik olarak incelenmesidir. Bu çalışmada anahtar kelime olarak "Preventing CLABSI infections" (Central Line-associated Bloodstream Infection=CLABSI) kullanılarak MEDLINE, CINAHL COCHRANE Library ve PUBMED veri tabanları taranmıştır. 1 Ocak 2016-08 Kasım 2020 tarihleri arasında uluslararası dergilerde yayınlanan çalışmalar değerlendirilmiş olup, yapılan tarama sonucunda 99 yayına ulaşılmıştır. Dahil edilme/çıkarılma kriterleri doğrultusunda yedi çalışma derleme kapsamına alınmıştır. İncelenen çalışmaların sonucunda, el hijyeni, kateter yerleştirilmesi sırasında maksimum bariyer önlemlerine uyulması, \%2'lik klorheksidin ile cilt antisepsisi, uygun pansuman uygulaması, femoral venden kaçınma ve günlük kateter gerekliliğinin sorgulanması gibi kanıta dayalı enfeksiyon kontrol önlemlerinin uygun yöntemler aracılığıyla uygulanmasının santral kateter ilişkili kan dolaşımı enfeksiyonlarını önlemede etkin olduğu saptanmıştır. Bu sistematik derlemenin sonucunda, santral kateter ilişkili kan dolaşımı enfeksiyonu insidansının düşürülmesi için kanıta dayalı enfeksiyon kontrol önlemlerinin özellikle yetişkin yoğun bakım ünitelerinde uygun yöntemler eşliğinde uygulanmaya devam edilmesinin gerekliliği saptanmıştır.

Anahtar Kelimeler: Kan dolaşımı enfeksiyonu, kateter, yoğun bakım

\section{Abstract}

The purpose of this review is to systematically review the intervention studies conducted and published to prevent central catheter-related bloodstream infections. In this study, MEDLINE, CINAHL COCHRANE Library and PUBMED databases were searched using "Preventing CLABSI infections" (Central Line-associated Bloodstream Infection $=\mathrm{CLABSI}$ ) as a keyword. Studies published in international journals between January 1,2016 and November 08,2020 were evaluated, and 99 publications were reached as a result of the search Seven studies were included in the scope of the review in line with the inclusion / exclusion criteria. As a result of the investigated studies, the application of evidence-based infection control measures such as hand hygiene, adherence to maximum barrier precautions during catheter insertion, skin antisepsis with $2 \%$ chlorhexidine, appropriate dressing, avoiding the femoral vein and questioning the need for daily catheters through appropriate methods It has been found to be effective in preventing associated bloodstream infections. As a result of this systematic review, it was determined that evidence-based infection control measures should be continued to be applied in adult intensive care units, especially in adult intensive care units, in order to reduce the incidence of central catheter-associated bloodstream infections.

Key words: Bloodstream infection, catheter, intensive care
Atıf yapmak için: Acun A, Çalışkan N. Yetişkin Yoğun Bakım Ünitelerinde Santral Kateter İlişkili Kan Dolaşımı Enfeksiyonlarının Önlenmesi: Sistematik Derleme. Selcuk Med J 2021;37(4): 378-385
Açıklama: Yazarların hiçbiri, bu makalede bahsedilen herhangi bir ürün, aygıt veya ilaç ile ilgili maddi çıkar ilişkisine sahip değildir. Araştırma, herhangi bir dış organizasyon tarafından desteklenmedi. Yazarlar çalışmanın birincil verilerine tam erişim izni vermek ve derginin talep ettiği takdirde verileri incelemesine izin vermeyi kabul etmektedirler. 


\section{Gíriş}

Santral venöz kateterizasyon (SVK), genellikle yoğun bakım üniteleri (YBÜ), ameliyathane, acil servis gibi kritik bakım noktalarında yaygın olarak kullanılan invaziv işlemlerden biridir (1). SVK, uzun süreli sıvı elektrolit replasmanı, hemodinamik izlem, kemoterapi ve parenteral beslenme, kan transfüzyonu gibi gereksinimler amacıyla özellikle YBÜ'lerde giderek daha sık kullanılmaktadır (2). SVK'nın artan endikasyonu hastaların tedavi süreçlerinde kaçınılmaz olmakla birlikte pek çok riski de beraberinde getirmektedir (3). Bu risklerin başında, Santral Kateter İlişkili Kan Dolaşımı Enfeksiyonları (SKI-KDE) gelmektedir (4).

SKİ-KDE'ler hakkında literatür incelendiğinde, Amerika Birleşik Devletleri'nde YBÜ'lerde her yıl 80.000 SKİ-KDE vakasının tespit edildiği, Avrupa ülkelerinde, 1000 SVK gününde Fransa'da 1,2, İngiltere'de 4,2 düzeyinde SKİ-KDE insidansı saptandığı görülmektedir (5). Gelişmekte olan ülkelerde, özellikle Latin Amerika'da, SKI-KDE'lerin boyutu tam olarak bilinmemekle birlikte Brezilya'da yapılan çalışmalarda, YBÜ hastalarında SKİ-KDE insidans yoğunluğunun yıllar içinde azaldığı tespit edilmiştir (1-5). Ülkemizde ise, 2019 yılı verilerine göre SKI-KDE insidansı 1000 kateter gününde 4,79 ile 7,99 arasında değişmektedir (6).

Sağlık hizmeti verilen tüm alanlarda olduğu gibi özellikle YBÜ'lerde SVK ilişkili enfeksiyonlar, hastalar için hastanede kalış süresinin artması, morbidite, mortalite ve antibiyotik direncinde artışa neden olurken kurumlar açısından ise özellikle maliyet artışı gibi pek çok olumsuz sonuca neden olmaktadır (5). Hastalarda kan dolaşımı enfeksiyonları ile, beyin fonksiyonlarında gerileme, hipoksik beyin, ekstremitelerde dolaşım bozukluğu ve buna bağlı amputasyonlar gibi hayati komplikasyonların yanı sıra uzun süre hastanede yatış, yaşam kalitesinde düşme, fazla dozda antibiyotik kullanımı gibi pek çok olumsuz sonuç görülmektedir $(2,3,5)$. Ayrıca SKİKDE'ler kurumları, ileri tanı testleri, yatak başı artan ücret ve ilaç kullanımında artış gibi ek maliyetlerle zarara uğratmaktadır (1-5). Gerek hastaların yaşadığı olumsuz sonuçları engellemek gerekse sağlık kurumlarının zararlarını önlemek amacıyla, SKİKDE'leri önlemede enfeksiyon kontrol önlemlerinin uygulanması ve SKİ-KDE'leriönleme yöntemleri büyük önem arz etmektedir (1). Centers for Disease Control and Prevention (CDC), Türk Hastane İnfeksiyonları ve Kontrolü Derneği gibi kuruluşların yayınladığı, yüksek düzeyde önerilen, iyi tasarlanmış deneysel, klinik veya epidemiyolojik çalışmalar ve kuvvetli bir teorik temel ile yapılanmış kanıtlardan oluşan kılavuzlarda yer alan kateter yerleştirme ve kateter bakım sürecine ilişkin etkin enfeksiyon kontrol programları SKİ-KDE'leri önlemede önemli bir yere sahiptir (79). SKİ-KDE'leri önleme adına kateter bakımında maksimum steril bariyer önlemlerin uygulanması, cilt antisepsisinde klorheksidin kullanımı, pansuman değişimi, sağlık profesyonellerinin eğitimi, SVK'nın rutin olarak değişiminin yapılmaması, el hijyenine uyum, SVK yerleştirilmesi için uygun bölgenin seçimi, femoral venin kullanımından kaçınılması gibi belirli kurallar uygun yöntemlerle uygulandığında etkili olmaktadır. SKİ-KDE'leri önlemede uyulması gereken enfeksiyon kontrol önlemleri kanıt düzeyi yüksek kılavuzlarda açık bir şekilde yer almasına karşın yapılan araştırmalarda, hastaların sadece yarısının güncel bilimsel kanıtlar doğrultusunda önerilen tıbbi bakımı aldıkları saptanmıştır. Ayrıca, kanıta dayalı uygulamalara yönelik enfeksiyon kontrol önlemlerinin klinik alanda uygulamaya koyulamamasının en önemli nedenlerinin bilgi eksikliği, sağlık profesyoneli kısıtılığı ve tıbbi malzeme eksikliği olduğu ortaya konulmuştur $(2,3,5)$.

Enfeksiyon kontrol önlemlerinin belirli olması kadar hangi yöntemlerle uygulandığı da enfeksiyon insidansında önemli bir yer tutmaktadır. Bu çalışmanın özelliği yetişkin YBÜ'lerde SKİ-KDE'leri önleme amacıyla uygulanan kanıt temelli müdahale yöntemlerine odaklanmasıdır. Mevcut enfeksiyon kontrol önlemlerinin birlikte kullanıldığı yöntemler, enfeksiyon insidansı açısından gözden geçirilmeli ve olumlu sonuçlar dahilinde yöntemlerin sürdürülebilirliği sağlanmalıdır. Kanıt temelli etkin enfeksiyon kontrol çalışmaları SKİ-KDE'lerin olumsuz sonuçlarını en aza indirerek hastalardaki yaşam kalitesini arttıracaktır. Bu doğrultuda bu sistematik derleme, SKİ-KDE'leri önlemeye yönelik yapılan ve yayınlanan müdahale çalışmalarının enfeksiyon insidansına etkisi açısından literatürü gözden geçirmek ve elde edilen sonuçların sistematik olarak incelenmesi amacıyla yapılmıştır. Bu amaç doğrultusunda sistematik derlemede cevap aranacak sorular şunlardır:

1. Yetişkin YBÜ'lerde SKI-KDE'leri önlemede kullanılan yöntemler nelerdir?

2. Bundle (önlem paketi) çalışmaları SKİ-KDE’leri önlemede yetişkin YBÜ'lerde etkili midir?

3. Enfeksiyon kontrol önlemlerinden oluşan kontrol listeleri yetişkin YBÜ'lerde SKİ-KDE'leri önlemede etkili midir? 


\section{GEREÇLER VE YÖNTEM}

$\mathrm{Bu}$ çalışma, SKİ-KDE'leri önlemeye yönelik yapılan çalışmaları incelemek amacıyla planlanmış bir sistematik derlemedir. Belirlenen zaman aralığında yayınlanan çalışmalar tek kişi tarafından taranmış ve tarama farklı zamanlarda üç kez tekrar edilmiştir. YBÜ sürecindeki hastalara ait tedavi uygulamalarının ve sağlık hizmeti ilişkili enfeksiyonların sürekli değişen dinamik bir süreç olmasından dolayı literatürde son beş yıl taramaya alınmıştır. Enfeksiyon kontrol önlemlerinin SKİ-KDE hızında etkinliğini güçlü kanıtlarla doğrulama adına müdahale çalışmaları inceleme kapsamına alınmıştır. Bu doğrultuda 1 Ocak 2016-08 Kasım 2020 tarihleri arasında yayınlanan müdahale çalışmaları MEDLINE (Medical Literature Analysis and Retrieval System), CINAHL (Cumulative Index to Nursing and Allied Health Literature), COCHRANE Library (The Cochrane Collaboration) ve PUBMED veri tabanları kullanılarak taranmıştır. Literatürü taramak için anahtar kelime olarak "Preventing CLABSI infections" kullanılarak 99 yayına ulaşılmış ve özet bölümleri incelenmiştir. İnceleme sonucunda tekrar eden ve tam metnine ulaşılamayan yayınlar inceleme kapsamına alınmamış, toplamda 59 yayının tam metnine ulaşılıp incelenmiştir. Yapılan inceleme sonrasında yedi makale çalışma kapsamına alınmıştır. Araştırmanın güvenilirliğini sağlamak için tüm sayının \%10'u kadar olan 10 veri rasgele bir şekilde seçilip dahil edilme kriterleri açısından incelenmiş ve değerlendirmeler arasında \%100'lük bir

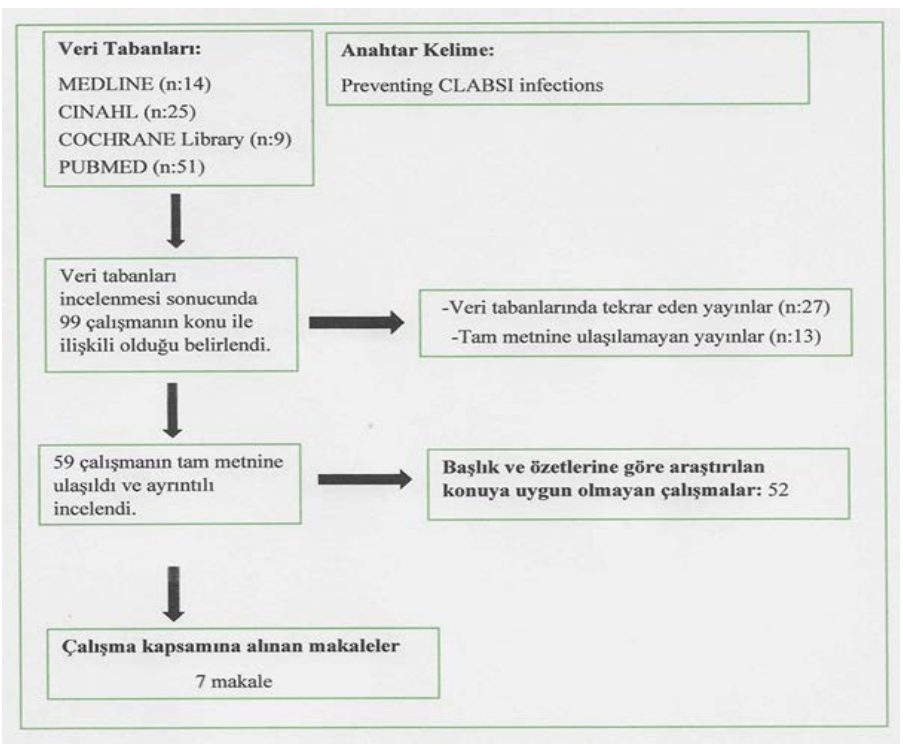

Şekil 1. Preferred Reporting Items for Systematic Reviews and Meta-Analyses (PRISMA) akış şeması uyum olduğu tespit edilmiştir. Çalışma PRISMA 2020 kontrol listelerine uygun olarak gözden geçirilmiştir. Sistematik İncelemeler ve Meta Analizler (PRISMA) için Tercih Edilen Raporlama Öğeleri (PRISMA) akış şeması oluşturulmuştur (Şekil 1.).

\section{Çalışmaya Dahil Edilme Kriterleri}

1. 1 Ocak 2016-08 Kasım 2020 tarihleri arasında uluslararası dergilerde yayımlanmış çalışmalar,

2. Deneysel ve kantitatif nitelikte yapılan çalışmalar,

3. Yayın dili İngilizce olan çalışmalar,

4. SKİ-KDE'leri önlemeye yönelik yetişkin YBÜ'de yapılan müdahale çalışmaları derleme kapsamına alınmıştır.

\section{Çalışmanın Dışlanma Kriterleri}

1. İngilizce dışı farklı dillerde yayımlanmış çalışmalar,

2. Hemodiyaliz kateterleri ile yapılmış çalışmalar,

3. Pediatrik YBÜ, ameliyathane, acil servis, genel servis gibi alanlarda yapılmış çalışmalar,

4. Enfeksiyon kontrolü adına genel klorheksidin banyosunu konu alan çalışmalar,

5. SKİ-KDE'leri önlemeye yönelik tek bir enfeksiyon kontrol önlemi içeren çalışmalar,

6. Yalnızca SKİ-KDE'leri önlemeye özgü olmayan bundle çalışmaları,

7. Derleme, olgu sunumu, geçerlik-güvenilirlik niteliğindeki çalışmalar.

\section{BULGULAR}

Bu çalışmada yedi adet araştırma makalesi incelenmiştir. Çalışmaların özellikleri "yazar/yazarlar (yıl), başlık, araştırma tipi ve araştırmada kullanılan yöntem, örneklem, SKİ-KDE'leri yönelik incelenen enfeksiyon kontrol önlemleri ve bulgular" başlıkları altında Tablo 1'de verilmiştir.

\section{Örneklem Özellikleri}

İncelenen çalışmaların yayın tarihinin, 2016-2018 tarihleri arasında olduğu belirlenmiştir. Derleme kapsamında incelenen çalışmalar yöntem bölümleri incelendiğinde SKİ-KDE'leri önlemek amacıyla genellikle bundle çalışmaları (4 çalışma) ve enfeksiyon kontrol önlemleri dahilinde oluşturulan kontrol listesi (1 çalışma) ve müdahale çalışmaları (2 çalışma) görülmüştür. Çalışmaların dünyanın farklı yerlerinde genellikle Dahili ve Cerrahi yetişkin YBÜ'lerde (Türkiye, Kuveyt, Şili, Brezilya, ABD, Avrupa bölgesi, Almanya), müdahale öncesi, müdahale dönemi ve sonrasını içeren süreçlerle yapıldığı gözlenmiştir. Çalışmaların altı tanesinin prospektif tipte, bir tanesinin ise randomize kontrollü tipte olduğu tespit edilmiştir. 


\section{SKI-KDE'yi Önlemede Bundle Çalışmaları}

Bundle, belirli bir enfeksiyonun iyileşme sürecini olumlu yönde etkileyen, etkinliği kanıtlanmış uygulamaların birkaç girişim veya müdahale şeklinde bir arada uygulanması yöntemidir (10). SKİ-KDE'leri önlemede etkinliği kanıtlanmış, el hijyenine uyum, kateter yerleştirme aşamasında maksimum bariyer önlemlerinin uygulanması, deri antisepsisinde klorheksidin kullanımı, uygun pansuman değişimi, sağlık profesyonellerinin eğitimi, SVK'nın rutin olarak değişiminin yapılmaması, SVK yerleştirilmesi için uygun bölgenin seçimi, femoral venin kullanımından kaçınılması gibi enfeksiyon kontrol önlemlerinin birkaçının "ya hep ya hiç yasası" ile uygulanması SKIKDE'leri önlemede etkin sonuçlar vermektedir (7-10).

Derleme kapsamında incelenen ve bundle yöntemi ile yapılan çalışmalar kanıt düzeyi yüksek çalışmalar olup, müdahale öncesi duruma göre SKİKDE insidansında önemli ölçüde düşüş saptanan çalışmalardır (Tablo 1) (11-14). Çalışmalarda, bundle yönteminde uygulanan parametreler incelendiğinde, el hijyeni uyum oranları \%83-100, kateter yerleştirilmesi sırasında maksimum bariyer önlemlerine uyulması \%93-100, \%2'lik klorheksidin ile cilt antisepsisi $\% 83-100$, uygun pansuman uygulaması $\% 90-100$, femoral venden kaçınma \%90-100 ve günlük SVK

Tablo 1. Değerlendirilmeye alınan çalışmaların özellikleri

\begin{tabular}{|c|c|c|c|c|c|}
\hline Sıra no & $\begin{array}{l}\text { Yazar/yazarlar } \\
\text { (yıl) }\end{array}$ & Başlık & $\begin{array}{l}\text { Araştırma tipi ve } \\
\text { araştırmada } \\
\text { kullanılan yöntem }\end{array}$ & Örneklem & $\begin{array}{l}\text { SKI-KDE'leri önlemeye yönelik incelenen enfeksiyon } \\
\text { kontrol önlemleri ve bulgular }\end{array}$ \\
\hline 1 & $\begin{array}{l}\text { Atilla A, } \\
\text { Doğanay Z, } \\
\text { Kefeli Çelik H } \\
\text { ve ark. (2016) } \\
(11)\end{array}$ & $\begin{array}{l}\text { Central } \\
\text { line-associated } \\
\text { bloodstream } \\
\text { infections } \\
\text { in the intensive } \\
\text { care unit: importance } \\
\text { of the care bundle }\end{array}$ & $\begin{array}{l}\text { Prospektif tipte, } \\
\text { Bundle yöntemi } \\
\text { ile yapılmış bir } \\
\text { müdahale çalışması }\end{array}$ & $\begin{array}{l}\text { Türkiye'de bir üniversite } \\
\text { hastanesinin } \\
\text { Dahiliye YBÜ } \\
\text { ve Cerrahi YBÜ }\end{array}$ & $\begin{array}{l}\text { Çalışma, Temmuz 2013-Haziran } 2014 \text { tarihleri arasında, müdahale öncesi, } \\
\text { müdahale dönemi ve müdahale sonrası dönemlerini kapsayacak şekilde toplamda } \\
114 \text { hasta ile yapılmışıtır. Uygulanan bundle parametreleri: 1) El Hijyeni, 2) \%2'lik } \\
\text { klorheksidin ile cilt antisepsisi, 3) Kateterin takımı sırasında maksimum bariyer } \\
\text { önlemleri, 4) Kateter yeri seçimi. Uygulanan müdahale sonrası, SKI-KDE hı̈ı } 1000 \\
\text { kateter gününde, Dahiliye YBÜ'de 6,2'den 1,05'e }(p<0,004) \text {, Cerrahi YBÜ'de ise } \\
8,27 \text { 'den } 3,73 \text { 'e }(p<0,194) \text { gerilemiştir. }\end{array}$ \\
\hline 2 & $\begin{array}{l}\text { Salamaa MF, } \\
\text { Jamal W, } \\
\text { Al Mousa H } \\
\text { ve ark. }(2016) \\
(12)\end{array}$ & $\begin{array}{l}\text { Implementation of } \\
\text { central venous catheter } \\
\text { bundle in an intensive } \\
\text { care unitin Kuwait: } \\
\text { Effect on central } \\
\text { line-associated } \\
\text { bloodstream infections }\end{array}$ & $\begin{array}{l}\text { Prospektif tipte, } \\
\text { Bundle yöntemi ile } \\
\text { yapılmış bir } \\
\text { müdahale çalışması }\end{array}$ & $\begin{array}{l}\text { Kuveyt Üniversitesi, } \\
\text { Sağlık Bilimleri } \\
\text { Merkezi Dahili ve } \\
\text { Cerrahi YBÜ }\end{array}$ & $\begin{array}{l}\text { Çalışma, Ocak 2010-Ocak } 2011 \text { tarihleri arasında müdahale öncesi, Şubat 2011- } \\
\text { Şubat } 2012 \text { tarihleri arasında ise müdahale dönemi ve müdahale sonrası } \\
\text { dönemlerini kapsayacak şekilde } 23 \text { yatak kapasiteli YBÜ'de yapılış̧tı. Uygulanan } \\
\text { bundle parametreleri: 1) El hijyeni, 2) Kateter yerleştirmede maksimum bariyer } \\
\text { önlemlerine uyma, 3) \%70'lik Etanol ile cilt antisepsisi, 4) Femoral venden } \\
\text { kaçınma, 5) Günlük kateter gerekliliğinin değerlendirilmesi. } \\
\text { Uygulanan müdahale sonrası YBÜ'de, SKI-KDE hızı } 1000 \text { kateter gününde } \\
\text { 14,9'dan 11,08'e }(p<0,0859) \text { gerilemiştir. }\end{array}$ \\
\hline 3 & $\begin{array}{l}\text { Fortunatti CFP. } \\
(2017)(13)\end{array}$ & $\begin{array}{l}\text { Impact of two bundles } \\
\text { on central catheter- } \\
\text { related bloodstream } \\
\text { infection in critically } \\
\text { ill patients }\end{array}$ & $\begin{array}{l}\text { Prospektif tipte, } \\
\text { Bundle yöntemi ile } \\
\text { yapılmış bir } \\
\text { müdahale çalışması }\end{array}$ & $\begin{array}{l}\text { Şili Santiago'da } \\
\text { bir eğitim hastanesi } \\
\text { Dahili ve Cerrahi YBÜ }\end{array}$ & $\begin{array}{l}\text { Çalışma, Ocak-Haziran } 2016 \text { tarihleri arasında müdahale ve Temmuz-Aralık } 2016 \\
\text { tarihleri arasında müdahale sonrasını kapsayacak şekilde } 32 \text { yataklı bir YBÜ'de } \\
\text { toplamda } 390 \text { hasta ile yapılmıştır. Çalışmada üçer parametreden oluşan kateter } \\
\text { yerleştirme ve bakım bundle kullanılışır. Kateter yerleştirme bundle } \\
\text { parametreleri: 1) El hijyeni, 2) \%2'lik klorheksidin ile cilt antisepsisi, 3) Kateter } \\
\text { yerleştirmede maksimum bariyer önlemlerinin alınması. Bakım bundle parametreleri } \\
\text { ise: 1) Günlük kateter gerekliliğinin değerlendirilmesi, 2) \%2'lik klorheksidin ile } \\
\text { kateter pansumanı, 3) Kateter yerleştirilen alanın değerlendirilmesi. } \\
\text { Uygulanan müdahale sonrası YBÜ'de, SKI-KDE hızı } 1000 \text { kateter gününde } \\
\text { 3,48'den 1,52'ye }(p<0,01) \text { gerilemiştir. }\end{array}$ \\
\hline 4 & $\begin{array}{l}\text { Assis DB, } \\
\text { Madalosso G, } \\
\text { Padoveze MC } \\
\text { ve ark. (2018) } \\
(16)\end{array}$ & $\begin{array}{l}\text { Implementation of } \\
\text { tailored interventions } \\
\text { in a statewide } \\
\text { programme to reduce } \\
\text { central line-associated } \\
\text { bloodstream infections }\end{array}$ & $\begin{array}{l}\text { Prospektif tipte yapılmış } \\
\text { bir müdahale çalışması }\end{array}$ & $\begin{array}{l}\text { Brezilya'nın Sao } \\
\text { Paula Eyaletinde } \\
\text { aynı düzeyde } \\
\text { yetişkin YBÜ } \\
\text { bulunan } 77 \text { hastane }\end{array}$ & $\begin{array}{l}\text { Çalışma, müdahale öncesi, müdahale dönemi ve sonrasını içeren iki döngüde } \\
\text { gerçekleştirilmiştir. } 2013 \text { yılı müdahale öncesini içerirken } 2015-2016 \text { yılları } \\
\text { müdahale ve sonrasını kapsamıştır. SKi-KDE'yi düşürmede etkili yöntemlerin } \\
\text { değerlendirildiği birinci döngüde } 56 \text { hastane ile çalışılmıştır. Daha sonrasında } 26 \\
\text { kişilik bir ekip eşliğinde el hijyeni, kişisel koruyucu ekipman kullanımına dikkat } \\
\text { edilmesi, kateter takımında maksimum bariyer önlemlerine uyum, uygun pansuman } \\
\text { gibi önlemler ile toplam } 77 \text { hastanede müdahale süreci uygulanmış ve sonrasında } \\
\text { değerlendirme yapılmıştır. Uygulanan müdahale sonrası } 77 \text { hastanede, SKI-KDE } \\
\text { hızı } 1000 \text { kateter gününde } 10,0^{\prime} \text { 'dan } 6,5 \text { 'e }(p<0,05) \text { gerilemiştir. }\end{array}$ \\
\hline 5 & $\begin{array}{l}\text { Kooi T, Sax H, } \\
\text { Pittet D ve ark. } \\
(2018)(17)\end{array}$ & $\begin{array}{l}\text { Prevention of hospital } \\
\text { infections by intervention } \\
\text { and training (PROHIBIT): } \\
\text { results of a pan-European } \\
\text { cluster-randomized } \\
\text { multicentre study to } \\
\text { reduce central venous } \\
\text { catheter-related } \\
\text { bloodstream infections }\end{array}$ & $\begin{array}{l}\text { Randomize kontrollü } \\
\text { tipte bir çalışma }\end{array}$ & $\begin{array}{l}11 \text { Avrupa ülkesindeki } \\
14 \text { hastanenin } \\
\text { yetişkin YBÜ'leri }\end{array}$ & $\begin{array}{l}\text { Çalışma, Ocak } 2011 \text {-Haziran } 2013 \text { tarihleri arasında, altı aylık bir müdahale öncesi } \\
\text { dönemden sonra toplamda } 25348 \text { hastanın dahil edildiği bir çalışma olarak } \\
\text { yürütülmüştür. Çalışmada, el hijyeni uyumu, SVK'nın uygun koşullarda } \\
\text { yerleştirilmesi ve enfeksiyon kontrol önlemlerinin enfeksiyon hızına etkisi } \\
\text { gözlenmiştir. Çalışmanın sonucunda enfeksiyon hızının düştüğü fakat sağlık } \\
\text { profesyonellerinin el hijyeni uygulamalarında yetersiz kaldıkları saptanmıştır. } \\
\text { Uygulanan müdahale sonrası tüm hastanelerde toplam olarak, SKI-KDE hızı } \\
1000 \text { kateter gününde } 2,4 \text { 'den } 0,9 \text { 'a }(p<0,0001) \text { gerilemiştir. }\end{array}$ \\
\hline 6 & $\begin{array}{l}\text { McCraw B, } \\
\text { Crutcher T, } \\
\text { Polancich S } \\
\text { ve ark. (2018) } \\
(14)\end{array}$ & $\begin{array}{l}\text { Preventing Central } \\
\text { Line-Associated } \\
\text { Bloodstream Infections } \\
\text { in the Intensive Care } \\
\text { Unit: Application of } \\
\text { High-Reliability Principles }\end{array}$ & $\begin{array}{l}\text { Prospektif tipte, } \\
\text { Bundle yöntemi } \\
\text { ile yapılmış bir } \\
\text { müdahale çalışması }\end{array}$ & $\begin{array}{l}\text { Amerika'nın } \\
\text { güneydoğusunda } \\
\text { bir akut bakım } \\
\text { hastanesi yetişkin } \\
\text { YBÜ }\end{array}$ & $\begin{array}{l}\text { Çalışma, Nisan-Haziran } 2016 \text { tarihleri arasında müdahale öncesi, Nisan-Haziran } \\
2017 \text { tarihleri arasında ise müdahale sonrası dönem şeklinde } 18 \text { yataklı bir YBÜ'de } \\
\text { uygulanmıştır. Çalışmada, lider bir ekip eşliğinde bir bakım bundle oluşturulması, } \\
\text { günlük kateter kontrolünün sağlanması, enfeksiyon kontrol önlemleri dahilinde } \\
\text { kontrol listesinin oluşturulması ve günlük uygulanması sağlanmıştır. Uygulanan } \\
\text { müdahale sonrası, SKI-KDE hızı } 1000 \text { kateter gününde, üçer aylık müdahale } \\
\text { dönemleri bazında 5,8'den 0'a, yıllık ise } 3,95 \text { 'den 2,83'e gerilemiştir. }\end{array}$ \\
\hline 7 & $\begin{array}{l}\text { Wichmann D, } \\
\text { Campos CEB, } \\
\text { Ehrhardt S } \\
\text { ve ark. (2018) } \\
(15)\end{array}$ & $\begin{array}{l}\text { Efficacy of introducing } \\
\text { a checklist to reduce } \\
\text { central venous line } \\
\text { associated bloodstream } \\
\text { infections in the ICU } \\
\text { caring for adult patients }\end{array}$ & $\begin{array}{l}\text { Prospektif tipte, kontrol } \\
\text { listesi yöntemi ile bir } \\
\text { müdahale çalışması }\end{array}$ & $\begin{array}{l}\text { Hamburg Eppendorf, } \\
\text { Almanya Hamburg } \\
\text { Üniversitesi Tıp } \\
\text { Merkezi'nde bir } \\
\text { YBÜ }\end{array}$ & $\begin{array}{l}\text { Çalışma, Ekim } 2011 \text {-Eylül } 2012 \text { tarihleri arasında SKi-KDE oranını ve kateter } \\
\text { kolonizasyonunu azaltmaya yönelik bir kontrol listesi eşliğinde uygulanmıştır. } \\
\text { Çalışma süresince, } 4416 \text { kateter takılmış ve } 2898 \text { kontrol, } 1518 \text { kateter ise kontrol } \\
\text { listesi eşliğinde takılmıştır. Kontrol listesi içerisinde, el hijyeni, kateter } \\
\text { takıımasında maksimum bariyer önlemleri, kateter için kesin endikasyon şartı, } \\
\text { femoral venden kaçınma, cilt antisepsisi, kateterin acil şartlarda takılıp takılmadığı, } \\
\text { kateter tipi gibi maddeler yer almıştır. Uygulanan müdahale sonrasında, SKI-KDE } \\
\text { hızı } 1000 \text { kateter gününde } 5,9^{\prime} \text { 'dan } 3,8^{\prime} \text { 'e }(p<0,001) \text { gerilemiştir. }\end{array}$ \\
\hline
\end{tabular}


gerekliliğinin sorgulanması \%85-100 oranlarında değişiklik gösterdiği saptanmıştır (11-14).

\section{SKi-KDE'yi Önlemede Uygulanan Müdahale ve Kontrol Listesi Çalışmaları}

Kontrol listeleri, bilgi aktarımından ziyade uygulama sürecini ve kurallara uyulup uyulmadığını ölçmede kullanılan araçlardır (15). Birçok alanda kullanılabildiği gibi sağlık hizmetinin verildiği alanlarda da kontrol listelerinin kullanılması sağlık profesyonellerinin performansını olumlu yönde etkilemektedir. İncelemeye alınan çalışmalar güçlü bir teorik alt yapı ile oluşturulan kanıt düzeyi yüksek kontrol listesi müdahale çalışmalarıdır. Çalışmalar arasında Wichmann ve arkadaşlarının (2018) SKİ-KDE'leri önlemeye yönelik enfeksiyon kontrol önlemlerinden oluşan bir kontrol listesi uygulaması gerek SVK yerleştirilmesi esnasında gerekse kateter bakımı sağlamada olumlu yönde etkili olmuş ve enfeksiyon insidansını düşürmüştür (15).

İncelemeye alınan diğer çalışmalar arasında, Assis ve arkadaşları (2018) 26 kişilik bir ekip ile SKI-KDE'leri önlemede enfeksiyon kontrol önlemlerini yönetim politikası anlayışıyla uygulamışlardır. Toplam 77 hastanede ve iki döngü şeklinde uygulanan çalışmanın tüm sürecindeki önlemlere uyum incelendiğinde, el hijyeni uyum oranları \%96-100, kateter yerleştirilmesi sırasında maksimum bariyer önlemlerine uyulması \%93-96, \%2'lik klorheksidin ile cilt antisepsisi \%8498 , uygun pansuman uygulaması $\% 92-94$ oranlarında belirlendiği saptanmıştır (16). Kooi ve arkadaşlarının (2018) uyguladıkları bir diğer çalışmada ise, 14 hastanede uygulama süresi sonunda enfeksiyon oranı gerilemiş, uygulama süresince kateterin uygun koşullarda takılması \%60'tan \%90 oranına çıkarken, el hijyeni uyumunun \%63 oranında kaldığı görülmüştür (17).

\section{TARTIŞMA}

$\mathrm{Bu}$ sistematik derlemenin amacı SKİ-KDE'leri önlemeye yönelik yapılan çalışmaların incelenmesidir. Dahil edilme/dışlanma kriterlerine göre incelemeye alınan yedi çalışma prospektif (altı çalışma) ve randomize kontrollü (bir çalışma) tipte olup, bundle, kontrol listesi ve SKİ-KDE'yi önleyici enfeksiyon kontrol önlemleri dahilinde yetişkin YBÜ'lerde uygulanan müdahale çalışmalarıdır. İncelenen çalışmalarda kanıta dayalı enfeksiyon kontrol önlemlerinin uygulanması sonucu SKİKDE insidansında düşüş saptanmıştır (11-17).

Literatür incelendiğinde, belirli enfeksiyon kontrol önlemleri doğrultusunda uygulanan müdahale çalışmalarının SKİKDE'leri önlemede başarılı olduğu görülmektedir (2-5, 17-22). Kılavuzlarda yer alan bilgiler dahilinde yapılan çalışmalarda SKiKDE'leri önleme stratejilerinin, kateter yerleştirme ve kateter bakımına odaklandığı görülmektedir. Kateter yerleştirilmesi ve bakımına yönelik SKİKDE'leri önleme stratejileri aşağıda iki başlık altında incelenmektedir.

\section{Santral Venöz Kateterin Yerleştirilmesi}

Sağlık hizmetinin verildiği alanlarda özellikle de YBÜ'lerde hemodinamik monitörizasyonun ve damar duvarını etkileyecek türde ilaç uygulamalarının (vazopressor, kemoterapi, parenteral nütrisyon)gerekli olduğu hastalarda santral venöz kateter endikasyonu söz konusu olmaktadır $(1,2,6,7)$. Santral venöz kateterizasyon uygulanacak olan hastada, kateter tipi ve kateter bölgesi seçimi, kateter yerleştirilmesi aşamasında enfeksiyon kontrol önlemlerine uyulması SKİ-KDE'leri önlemede büyük önem taşımaktadır $(7,8)$. Kateterle ilişkili enfeksiyonların azaltılmasında seçilecek kateterin tipi önemli olup, kateterin yapıldığı materyal, enfeksiyon gelişimini etkileyebilmektedir. Politetrafluroetilen (teflon) ve poliüretan kateterler; polivinil klorid veya polietilen olanlara göre daha az enfeksiyon riskine sahiptir (7). Amerika'da, 16 eyalette ve Porto Riko'da 220 hastane, 366 yoğun bakım ünitesinde SKİ-KDE'leri önlemeye yönelik yapılan çalışmada teflon içerikli tünelli kateterlerin mikrobik kolonizasyon açısından güvenli olduğu sonucuna varılmıştır (23). SKİ-KDE riski açısından önem taşıyan bir diğer nokta, kateterin lümen sayısı ve kateterin yerleştirildiği bölgedir (femoral>juguler>subklavyen). Kateter yerleştirilmesinde cilt flora yoğunluğunun az olduğu bölgenin seçilmesi gerekmektedir $(7,8)$. Kanıt düzeyi yüksek nitelikte yapılan çalışmalarda özellikle erişkin YBÜ'lerde tespit edilen enfeksiyonların büyük çoğunlukla femoral bölgeye takılan kateterler aracılığıyla geliştiği saptanmış ve femoral bölgenin kullanımından kaçınılması sonucuna varılmıştır $(2-5,19,23)$. Santral venöz kateterizasyon sırasında ise eş zamanlı olarak ultrason kullanımı kılavuzlarda belirtilmektedir $(7,8)$. Ultrason, mekanik komplikasyonları en aza indirmesi açısından ve ven çapının ölçülmesi ile venöz tromboz riskinin düşürülmesi açısından önem arz etmektedir (8). Ultrason eşliğinde kateter bölgesini tespit ederek kateterizasyonun uygulandığı çalışmalarda mekanik travmanın azaltıımasının SKI-KDE oranları ile doğrudan ilişkili olduğu saptanmıştır $(24,25)$. Kateter yerleştirilmesi sırasında bir diğer önemli nokta maksimum bariyer önlemlerinin kullanılmasıdır. Maksimum bariyer 
önlemleri içerisinde steril önlük, steril eldiven, bone, maske ve steril tüm vücut örtüsü (ameliyathanede kullanılan örtülere benzer) kullanılması yer almaktadır $(7,8)$. Ayrıca, kateter yerleştirilecek olan bölgenin \%70'lik alkol içeren > \%0.5 klorheksidin solüsyonu ile silinmesi SKİ-KDE'leri önlemede üst düzeyde etkilidir $(7,8)$. Enfeksiyöz komplikasyonları azaltmak amacıyla kateter yerleştirilmesi sırasında maksimum bariyer önlemlerinin uygulanması kateter giriş yeri kontaminasyonunu azaltmaktadır (2). Kanıt düzeyi yüksek çalışmalar için literatür tarandığında gerek bundle gerekse kontrol listeleri ve SKIKDE'leri önleyici çalışmalarda kateter yerleştirilmesi sırasındaki cilt temizliği ve maksimum bariyer önlemlerinin uygulanmasının enfeksiyon hızını doğrudan etkilediğini göstermektedir (1-5, 11-23). Tüm enfeksiyon kontrol önlemlerinin yanı sıra SKİ-KDE'leri önlemede günlük SVK gerekliliğinin değerlendirilmesi ve uzun süreli kateterizasyondan kaçınılması da yer almaktadır. Yapılan çalışmalarda, SVK gün sayısının azaltılması ile SKİ-KDE oranının doğru orantılı bir şekilde düştüğü gösterilmiştir $(2,3,10,23)$.

Yukarıda verilen bilgiler ve yapılan müdahale çalışmalarının sonuçları dahilinde, SKİ-KDE'leri önlemede kateter yerleştirilmesi aşamasında uyulması gereken önemli noktalar aşağıda maddeler halinde sıralanmıştır $(7,8,11-25)$ :

Santral venöz kateter endikasyonunun dikkatli bir şekilde belirlenmesi

Hastanın genel durumuna uygun kateter tipinin ve kateter bölgesinin seçilmesi

Santral kateterin ultrason eşliğinde takılması

Kateter yerleştirilmesi sırasında maksimum bariyer önlemlerine uyum gösterilmesi

Kateter girişimi yapılacak bölgenin \%70'lik alkol içeren $>\% 0.5$ klorheksidin solüsyonu ile silinmesi ve 30 saniye kurumaya bırakılması

Kateter giriş yerinin şeffaf örtü veya giriş yerinde geçici süre kanama olması halinde steril gazlı bez ile baskılı bir şekilde kapatılması

\section{Santral Venöz Kateter Pansumanı ve Bakımı}

Santral venöz kateterin yerleştirilmesi sonrasında el hijyeninin sağlanması, uygun kateter pansumanının yapılması ve kateter giriş yeri çevresinin kızarıklık, şişlik, akıntı, hassasiyet, kanama yönünden gözlemlenmesi SKİ-KDE'leri önlemede önemli bir yer tutmaktadır $(7,8)$. Kateterin yerleştirilmesi esnasında ve kateter bakımı süresince el hijyeni sağlamanın SKİ-KDE'lerin önlenmesinde etkili olduğu çalışmalarla gösterilmiştir $(2-5,10)$. Kılavuzlarda ve kanıt düzeyi yüksek çalışmalarda, uygun el hijyeni yapıldığı takdirde ellerdeki kontaminasyonun azaldığı, bu durumun ise SKI-KDE'leri doğrudan etkilediği sonucuna varılmıştır (7,8,11-20). Yoshida et al. (3) Ocak 2012-Aralık 2015 tarihleri arasında yetişkin YBÜ'de uyguladıkları çalışmada, enfeksiyon kontrol önlemlerinin kateterin yerleştirilmesi esnasında eksiksiz uygulanmasının ve günlük kateter bölgesinin gözlemlenmesinin, kateter yüzeyindeki kolonizasyonu ve SKİKDE oranını düşürmede etkin olduğu saptanmıştır. Amerika Birleşik Devletleri'nin güney batısındaki üçüncü basamak bir hastanede, toplam altı yetişkin YBÜ'de Drews et al. (19) yaptıkları çalışmada, el hijyeni, kateter giriş yeri pansumanında cilt antisepsisi amacıyla \%70'lik alkol içeren $>\% 0,5$ klorheksidin solüsyonunun kullanılması (klorheksidin yok ise povidon iyodin $+\% 70$ alkol solüsyonu kullanıması) gibi enfeksiyon kontrol önlemlerinin SKİ-KDE'leri azaltmada başarılı olduğu görülmüştür. Kanıt düzeyi yüksek çalışmaların olduğu mevcut literatürde cilt antisepsisi açısından, \%70'lik alkol içeren $>\% 0,5$ konsantrasyondaki klorheksidin glukonadın, alkol içerikli antiseptik solüsyonlara ve povidon iyoda göre, cilt kontaminasyonunda daha etkili olduğu bildirilmektedir (20-25). \%70'lik alkol içeren $>\% 0,5$ konsantrasyondaki klorheksidin glukonat, kateter yerleştirme ve bakımında kolonizasyonunu engellemektedir $(21,22)$. Kateter takımı sonrası uygun kateter giriş yeri örtülerinin kullanılmasına ilişkin literatür incelendiğinde, kateter giriş yeri örtülerinin, SKİ-KDE'leri azaltmada etkili olduğu ve kateter giriş yeri kolonizasyonunu doğrudan azalttığını destekleyen çalışmalar görülmüştür (2-5). Crivelaro et al. (20) kateter bakımına odaklanan çalışmalarında ise, günlük kateter bakımının doğru uygulandığında SKİ-KDE insidansında önemli ölçüde azalma olduğu belirlenmiştir.

Yukarıda verilen bilgiler ve yapılan müdahale çalışmalarının sonuçları dahilinde, SKİKDE'leri önlemede kateter pansumanı ve bakımında uyulması gereken önemli noktalar aşağıda maddeler halinde sıralanmıştır $(7,8,11-20)$ :

Pansuman uygulamasına başlamadan önce ve kateter ile yapılacak tüm uygulamalarda el hijyenine maksimum uyumun sağlanması Hastanın genel durumu ve izolasyon durumuna göre kişisel koruyucu ekipmanların giyilmesi

Kateter giriş yerinin kızarıklık, şişlik, hassasiyet, akıntı, kanama gibi enfeksiyon bulguları yönünden değerlendirilmesi

Kateter pansumanı sırasında cilt antisepsisi amacıyla \%70'lik alkol içeren $>\% 0.5$ klorheksidin solüsyonunun kullanılması, klorheksidin bulunamadı- 
ğı durumlarda ise povidon iyodin $+\% 70$ alkol solüsyonunun kullanılması

Uygun kateter pansumanı için şeffaf, yarı geçirgen örtülerin 5-7 günde, gazlı bez örtülerin ise 48 saatte bir, kateter çevresinde akıntı, kanama durumu ve kirlilik var ise kateter örtüsünün hemen değiştirilmesi

Kateter pansumanının aseptik teknik çerçevesinde temiz veya steril eldiven ile uygulanması

Kateterin lümen açıklığının sağlanması, yıkama ve kilitleme amacıyla steril, koruyucu içermeyen serum fizyolojik kullanılması

Kullanılan üçlü muslukların kapalı tutularak, IV sıvı setlerinin ve bağlantı araçlarının uygun sürelerde değiştirilmesi gerekmektedir.

Derleme kapsamında incelenen çalışmalarda, literatürle benzer şekilde enfeksiyon kontrol önlemlerinin uygulandığı görülmüştür. Derleme kapsamına alınan çalışmalar yüksek düzeyde önerilen, kuvvetli bir teorik alt yapı ile tasarlanmış randomize kontrollü çalışma ve deneysel çalışmalardan oluşmaktadır. Kanıta dayalı enfeksiyon kontrol önlemlerinden oluşan bundle, kontrol listesi, müdahale girişimleri gibi sistemli bir şekilde uygulanan çalışmalar SKİ-KDE insidansının düşürülmesinde yüksek düzeyde geçerlilik olduğunu göstermektedir (11-17). Bundle çalışmaları ile birkaç girişimin bir arada uygulanması SKİ-KDE'leri önlemede etkin bir enfeksiyon kontrol programı oluşturmuştur. Kontrol listeleri ve müdahale çalışmaları ise özellikle işlem basamaklarına uyum konusunda pozitif bir etki sağlamış ve SKİ-KDE'leri önlemiştir (1117). Gerek bundle çalışmalarının gerekse kontrol listeleri ve müdahale çalışmalarının, SKİKDE'leri önlemede, sağlık profesyonellerine farkındalık kazandırdığı, kateter takımı ve bakımı sürecinde sağlık profesyonellerinin uygulamalarında hassasiyet oluşturduğu görülmektedir. Bu çalışmalarda, kanıta dayalı enfeksiyon kontrol önlemlerinin bir arada uygulanması, kontrol listesi oluşturulması çalışmaların güçlü yönünü göstermektedir. Uygulama öncesi ve sonrasındaki enfeksiyon insidansı farkı sağlık profesyonelleri ve yöneticilerini başarı olarak motive ederken hastalara ise yüksek yaşam kalitesi sunmaktadır. Enfeksiyon hızına müdahale eden çalışmalarda sağlık profesyonellerinin bilgi eksikliği ve hasta başı uygulamalarına ilişkin alışkanlıkları çalışmaların zayıf yönlerini oluşturmaktadır. $\mathrm{Bu}$ kapsamda, müdahale çalışmalarının sıkça tekrarlanmasının sağlık profesyonellerinin davranış değişikliği kazanmasında etkili olduğu görülmektedir. SVK'ların takım aşaması ve bakım sürecinde kanıta dayalı enfeksiyon kontrol önlemleri multidisipliner bir şekilde uygulandığında enfeksiyon insidansını önemli ölçüde azaltmaktadır. SKİ-KDE'leri önlemede özellikle YBÜ'lerde kanıta dayalı enfeksiyon kontrol önlemlerinin uygulanmasına devam edilmesi önerilmektedir.

Sonuç olarak; SKİ-KDE'lerin önlenmesi gerek mortalite ve morbidite gerekse hastanede kalış süresi, antibiyotik direnci ve hastane yükü açısından büyük önem taşımaktadır. Bu sistematik derleme, el hijyeni, kateter yerleştirilmesi sırasında maksimum bariyer önlemlerine uyulması, \%2'lik klorheksidin ile cilt antisepsisi, uygun pansuman uygulaması, femoral venden kaçınma ve günlük SVK gerekliliğinin sorgulanması gibi kanıta dayalı enfeksiyon kontrol önlemlerinin uygun yöntemler ile uygulandığında SKIKDE'leri önlemede etkin olduğunu göstermiştir. Bu sistematik derlemenin sonucunda, sıfır enfeksiyona ulaşmak için SKİ-KDE'leri önlemeye yönelik kanıtlanan enfeksiyon kontrol önlemlerinin özellikle yetişkin YBÜ'lerde uygulanmaya devam edilmesinin gerekliliği saptanmıştır.

*Bu çalışma Aysun Acun'un doktora tezinin bir bölümünden üretilmiştir.

Çıkar Çatışması: Çalışmada herhangi bir çıkar çatışması yoktur.

Finansal Çıkar Çatışması: Çalışmada herhangi bir finansal çıkar çatışması yoktur.

Yazışma Adresi: Aysun Acun, Bilecik Şeyh Edebali Üniversitesi, Sağlık Bilimleri Fakültesi, Hemşirelik Bölümü, Bilecik, Türkiye Phone: 05072104506

E-mail: aysun.acun@bilecik.edu.tr

\section{KAYNAKLAR}

1. Kıray S, Yıldırım D, Özçiftçi S, et al. Santral venöz kateter bakımı ve enfeksiyon: Bir sistematik derleme. Turk J Intense Care 2019;17:60-74.

2. Bekçibaşı M, Dayan S, Aslan E, et al. Risk factors for central venous catheter-related bloodstream infections. Infez Med 2019;3:258-65.

3. Yoshida T, Camargo Silva AEB, Pineli Simões LL, et al. Incidence of central venous catheter-related bloodstream infections: Evaluation of bundle prevention in two intensive care units in central Brazil. TSWJ 2019;1-8.

4. Paplawski S. Prevention of central line-associated bloodstream infections in the neonatal intensive care unit: $A$ literature review. J Neonatal Nurs 2020;26:142-8.

5. Özen N, Köse T, Terzioğlu F. Santral venöz kateter enfeksiyonlarının önlenmesinde kanıta dayalı uygulamalar: Yoğun bakım hemşirelerinin bilgileri. Turk $\mathrm{J}$ Intense Care 2020;18:91-8.

6. Hekimoğlu $\mathrm{CH}$, Batır E, Yıldırım Gözel E. Ulusal sağlık hizmeti ilişkili enfeksiyonlar sürveyans ağı özet raporu. T.C. Sağlık Bakanlığı Halk Sağlığı Genel Müdürlüğü Bulaşıcı 
Hastalıklar Dairesi Başkanlığı 2019;1-49.

7. Damar içi kateter infeksiyonlarının önlenmesi kılavuzu. Turk J Hosp Infect 2013;17(2):233-79.

8. Ulusal damar erişimi yönetimi rehberi. Turk $\mathrm{J}$ Hosp Infect 2019;23(1):26-54.

9. Guidelines for the prevention of intravascular catheter-related infections. CDC 2011;20-59.

10. Mobley RE, Bizzarro MJ. Central line-associated bloodstream infections in the NICU: Successes and controversies in the quest for zero. Semin Perinatol 2017;41:166-74.

11. Atilla A, Doğanay $Z$, Kefeli Çelik $H$, et al. Central lineassociated bloodstream infections in the intensive care unit: Importance of the care bundle. Korean J Anesthesiol 2016;69(6):599-603.

12. Salama MF, Jamal W, Al Mousa H, et al. Implementation of central venous catheter bundle in an intensive care unit in Kuwait: Effect on central line-associated bloodstream infections. J Infect Public Health 2016;9(1):34-41.

13. Fortunatti CFP. Impact of two bundles on central catheterrelated bloodstream infection in critically ill patients. Rev. REV LAT-AM ENFERM 2017;25:2957-64.

14. McCraw B, Crutcher T, Polancich S, et al. Preventing central line-associated bloodstream infections in the intensive care unit: Application of high-reliability principles. JHQR 2018;40(6):392-7.

15. Wichmann D, Campos CEB, Ehrhardt S, et al. Efficacy of introducing a checklist to reduce central venous line associated bloodstream infections in the ICU caring for adult patients. BMC Infec Dis 2018;18:267-73.

16. Assis DB, Madalosso G, Padoveze MC, et al. Implementation of tailored interventions in a statewide programme to reduce central line-associated bloodstream infections. J Host Infec 2018;100:163-8.

17. Kooi T, Sax H, Pittet D, et al. Prevention of hospital infections by intervention and training (PROHIBIT): Results of a panEuropean cluster-randomized multicentre study to reduce central venous catheter-related bloodstream infections. Intensive Care Med 2018;44:48-60.
18. Lutwick L, Al-Maani AS, Mehtar S, et al. Managing and preventing vascular catheter infections: A position paper of the international society for infectious diseases. J Infect Dis 2019;84:22-9.

19. Drews FA, Bakdash JZ, Gleed JR. Improving central line maintenance to reduce central line-associated bloodstream infections. AJIC 2017;45:1224-30.

20. Crivelaro N, Contrin LM, Beccaria LM, et al. Adhesıon of nursing to the blood current infection protocol. J Nurs UFPE 2018;12(9):2361-7.

21. Guenezan J, Drugeon B, O'Neill R, et al. Skin antisepsis with chlorhexidine-alcohol versus povidone iodine-alcohol, combined or not with use of a bundle of new devices, for prevention of short-term peripheral venous catheter-related infectious complications and catheter failure: an open-label, single-centre, randomised, four-parallel group, two-by two factorial trial: CLEAN 3 protocol study. BMJ 2019;1-8.

22. McCann M, Fitzpatrick F, Mellotte G, et al. Is $2 \%$ chlorhexidine gluconate in $70 \%$ isopropyl alcohol more effective at preventing central venous catheter-related infections than routinely used chlorhexidine gluconate solutions: A pilot multicenter randomized trial (ISRCTN2657745)? AJIC 2016;44:948-57.

23. Meddings J, Greene T, Ratz D, et al. Multistate programme to reduce catheter-associated infections in intensive care units with elevated infection rates. BMJ Qual Saf 2020;29:418-29.

24. "Schmidt GA, Blaivas M, Conrad SA, et al. Ultrasound-guided vascular access in critical illness. Intensive Care Med 2019;45:434-46.

25. Sidoti A, Brogi E, Biancofiore G, et al. Ultrasound- versus landmarkguided subclavian vein catheterization: $A$ prospective observational study from a tertiary referral hospital. Sci Rep 2019;9:12248. 